\title{
Determination of Acrylamide in Branded and Non-branded Potato Chips by using High Performance Liquid Chromatography
}

\author{
*NaseemZahra, Qurat-ul-Ain Syed, Imran Kalim, Zohaib Khurshid, \\ Ijaz Ahmad and Muhammad Khalid Saeed \\ Food and Biotechnology Research Centre, PCSIR Laboratories Complex, Ferozepur Road, Lahore-54600, Pakistan. \\ *Corresponding Author Email: naseem.zahra1981@gmail.com \\ Received 05 December 2017, Revised 21 May 2018, Accepted 24 May 2018
}

\begin{abstract}
Acrylamide, a starchy food process contaminant is carcinogenic, neurotoxic and genotoxic substance. It is formed at temperatures of $100^{\circ} \mathrm{C}-220^{\circ} \mathrm{C}$. The chips are very popular food items especially among children. Deep Frying of chips may cause production of acrylamide. The presence of acrylamide in chips may result in severe health issues in consumers especially in children. By keeping this aspect in view, the present study was conducted to determine acrylamide in different potato chips of branded and non-branded quality. The highest amount of acrylamide was determined in chips sample K obtained from local store (nonbranded) in Lahore i.e. 2649.80 $\mu \mathrm{g} / \mathrm{kg}$ and the lowest concentration of acrylamide was detected in sample taken from local vendor i.e. $390.25 \mu \mathrm{g} / \mathrm{kg}$. The astounding results were obtained as branded chips have considerable amount of acrylamide. Formation of acrylamide in fried chips is matter of concern as potato chips are widely consumed in Pakistan especially by children. It is dire need to have awareness of this probable carcinogen as consumers and industries still have no knowledge about this chemical's carcinogenity. Therefore, without delay work should be started to mitigate the acrylamide levels in food commodities during processing.
\end{abstract}

Keywords: Acrylamide, Potato, Chips, HPLC, Retention time.

\section{Introduction}

Acrylamide (AA) or 2-propenamide formed in a broad range of food products (oven cooked and fried foods) was discovered for the first time in $2002[1,2]$. The unearthing of acrylamide in foods raised great concerns for the reason that acrylamide has been classified a potent carcinogen [3]. Acrylamide in food is produced as a result of the Maillard reaction among asparagine and reducing sugars. Thus, the amount of acrylamide depends on the concentration of these antecedents in food samples, alongwith different processing conditions during food preparation and storage [4]. It is concluded that acrylamide is formed as a result of asparagine degradation by carbonyl (from glucose and fructose source) reaction $[5,6]$. There are many factors which may affect formation of acrylamide in potato and cereals products i.e. variety of raw materials, harvesting time, storage condition and fertilization [7-10]. The limiting factor in acrylamide formation process are reducing sugars, so it is better option to control reducing sugars and asparagine to reduce acrylamide concentration [11].

There are different procedures for the determination of acrylamide in food items i.e. liquid chromatography [12], gas chromatography [13] and mass spectrometry coupled with gas chromatography [14] or liquid chromatography [15]. HPLC is very good, low cost and sensitive 
technique to determine acrylamide concentration in potato chips by acetone extraction. It was found that in french fries acrylamide concentration levels increased as the oven temperature increased from $100-220^{\circ} \mathrm{C}$ and achieved a maximum level of $5000 \mu \mathrm{g} / \mathrm{kg}$ [16]. Acrylamide formation begins to start at $100^{\circ} \mathrm{C}$ and increases upto $220^{\circ} \mathrm{C}$ in processes like frying, roasting and baking. It is estimated by conducting risk assessment that daily intake of acrylamide is $0.2-0.8 \mathrm{mg} / \mathrm{kg}$ body weight [17].

According to European Union the acrylamide concentration was found high in processed foods like fried chips, potato chips, crispy bread, biscuits, breads and cereals [18]. Acrylamide in highest concentrations were detected in coffee (instant) and coffee substitutes. Although some food companies have taken necessary actions to reduce the amount of acrylamide in different products but overall scenario shows that more drastic efforts are needed to deal with this serious issue concerning public health [19]. The current study is conducted to determine acrylamide presence and concentrations in potato chips of branded, local bakery and street vendor quality.

\section{Materials and Methods Reagents}

All the chemicals and reagents used in the present study were purchased from Merck (Dermastd, Germany).

\section{Samples collection}

12 chips samples were purchased from local stores and bakeries. 8 samples were of two popular brands in Lahore, Pakistan while 4 samples were collected from local vendor and bakeries.

\section{Acrylamide extraction}

Acrylamide extraction was done by following method described [20] by Koshnam et al., 2010. Sample was crushed using mortar and pestle to homogenize the sample. $10 \mathrm{~g}$ sample was weighed using analytical weighing apparatus. $25 \mathrm{ml}$ of n-Hexane was added in flask containing sample to de-fat the sample by putting it on wrist action shaker for $10 \mathrm{~min}$. This step was repeated for thorough de- fattening. Hexane was decanted and sample was dried by using hot plate on moderate temperature. For extraction of acrylamide, $50 \mathrm{ml}$ of acetone and $100 \mu \mathrm{l}$ of distilled water in the sample were added. Flask was placed on water bath preset at $40^{\circ} \mathrm{C}$ for $20 \mathrm{~min}$. After $20 \mathrm{~min}$, acetone was filtered and half of it was evaporated by putting it on hot plate again. Suspended the residue in $5 \mathrm{ml}$ of distilled water and filtered it with 0.25 micron syringe filter for further HPLC analysis.

\section{Preparation of acrylamide standard solution}

Standard of Acrylamide (Sigma Aldrich) was purchased to carry out HPLC analysis. Stock solution for standard was prepared by weighing $10.70 \mathrm{mg}$ acrylamide precisely and dissolving in $50 \mathrm{ml}$ distilled water which makes concentration of sample $0.214 \mathrm{mg} / \mathrm{ml}$ or $214 \mathrm{ppm}$. Stock solution was further diluted to construct calibration graph for quantification and kept away from direct sunlight and stored under refrigeration.

\section{HPLC analysis}

Samples were analyzed by using HPLC Perkin-Elmer 200 Series with C-18 Column having $250 \mathrm{~mm}$ length, $4.6 \mathrm{~mm}$ diameter and 25 micron particle size. Column oven temperature was set at $40^{\circ} \mathrm{C}$ and flow rate was maintained at $1 \mathrm{ml} / \mathrm{min}$. The analysis was performed at $202 \mathrm{~nm}$ with a UV detector. First of all, standard solution was run and then samples were run and their retention time was compared with standard solution.

\section{Results and Discussion}

Acrylamide is not a matter that is added to food entities but it is formed in food during heat processing. Present research was designed to determine acrylamide in potato chips of branded and non branded type alongwith local shops of Lahore in October 2015-March 2016. Total 12 samples were checked in triplicate for the presence of acrylamide concentration. 
High performance liquid chromatographic technique was used to determine acrylamide in potato chips due to its effectiveness and reliable results. The mobile phases used were $80 \%$ acetonitrile and $20 \%$ distilled water. Standard acrylamide was determined with characteristic peak at 3.04 minutes of retention time. Limit of detection (LOD) and limit of quantification (LOQ) for the present method was 2.46 and $3.14 \mathrm{ng} \mathrm{g}^{-1}$, respectively [20].

In the study conducted by Geng et al., to analyze acrylamide in potato chips, LOD and LOQ values were 15 and $50 \mu \mathrm{g} / \mathrm{kg}$ correspondingly [21]. Hariri et al., 2015 looked into corn and potato chips for the detection of acrylamide and heavy metals. It was estimated that potato chips contained $25 \%$ more acrylamide than corn chips. Shocking fact was that acrylamide intake was 7-40 times greater than that of risk intake for causing cancer set by World Health Organization [22]. The results of acrylamide in potato chips and Average, maximum and minimum are given in Table 1.

Table 1. Results of acrylamide determination in potato chips by HPLC.

\begin{tabular}{|c|c|c|c|}
\hline $\begin{array}{l}\text { Sample } \\
\text { No. }\end{array}$ & Sample Code & $\begin{array}{c}\text { Mean } \\
\text { Retention } \\
\text { Time } \\
\text { (minutes) }\end{array}$ & $\begin{array}{c}\text { Mean } \\
\text { Quantity } \\
(\mu \mathrm{g} / \mathrm{kg}) \pm \text { S.D. }\end{array}$ \\
\hline S1 & Branded A & 3.37 & $905.00 \pm 1.000$ \\
\hline S2 & Branded B & 2.97 & $748.53 \pm 1.000$ \\
\hline S3 & Branded C & 2.78 & $821.36 \pm 1.000$ \\
\hline S4 & Branded D & 2.79 & $689.62 \pm 0.510$ \\
\hline \multirow{2}{*}{$\begin{array}{l}\text { S5 } \\
\text { S6 }\end{array}$} & Branded E & 3.22 & $547.04 \pm 0.031$ \\
\hline & $\begin{array}{l}\text { Branded } \\
\text { F (Imported) }\end{array}$ & 2.82 & $1002.86 \pm 1.010$ \\
\hline S7 & Branded G & 2.79 & $989.45 \pm 0.810$ \\
\hline S8 & Branded H (Imported) & 3.18 & $780.61 \pm 0.315$ \\
\hline S9 & $\begin{array}{l}\text { Local I- Non branded } \\
\text { (Vendor) }\end{array}$ & 3.20 & $390.25 \pm 0.510$ \\
\hline S10 & Local J- Non branded & 3.20 & $871.89 \pm 0.210$ \\
\hline S11 & Local K- Non branded & 3.17 & $2649.80 \pm 1.100$ \\
\hline $\mathrm{S} 12$ & Local L- Non branded & 2.97 & $458.74 \pm 0.510$ \\
\hline
\end{tabular}

D.D. $=$ Standard deriation of triplicate analysis
In an investigation; acrylamide concentration in food products purchased from Latvian local market. There were 8 sets of samples which consisted of rye based breads, wheat based breads, potato chips, coffee etc. Ultra high performance liquid chromatography attached with tandem mass spectrometric detector was used in this study [23]. Results had shown higher acrylamide concentration in foods which are processed e.g. potato chips and coffee as compared to unprocessed foods. Range of acrylamide concentration was from $564 \mu \mathrm{g} / \mathrm{kg}$ to $2790 \mu \mathrm{g} / \mathrm{kg}$ while on the other hand not any single bread have shown acrylamide presence higher than allowable limits except for the breads which contain seeds. More significantly, presence of fruits and vegetables in breads has an escalating outcome on acrylamide concentration.

In another study; the fried chips of brand kurkure was found to have the maximum acrylamide concentration when compared with other bakery and puff food stuff. Kurkure's acrylamide concentration was measured to be the highest due to various factors such as compositional difference and degree of frying when compared with other processed food products [24].

In current study, the highest amount of acrylamide was determined in chips sample $\mathrm{K}$ obtained from local store of Lahore i.e. 2649.80 $\mu \mathrm{g} / \mathrm{kg}$ and the lowest concentration of acrylamide was detected in sample I taken from local vendor i.e. $390.25 \mu \mathrm{g} / \mathrm{kg}$ while the branded samples also have considerable amounts of acrylamide also; which is notable (Fig. 1).

Similar studies were conducted to obtain the data on acrylamide in various food commodities from different companies and provided an overview regarding acrylamide situation and health hazards of branded cakes, biscuits and potato chips in Pakistan [25]. The concentrations of acrylamide in biscuits were found in the range of $52.3 \pm 0.70$ to $507.5 \pm 1.5$ $\mu \mathrm{g} / \mathrm{kg}$; while in cakes it was less while in potato chips the concentrations were between $27.1 \pm 0.65$ to $1323.0 \pm 3.0 \mu \mathrm{g} / \mathrm{kg}$. 


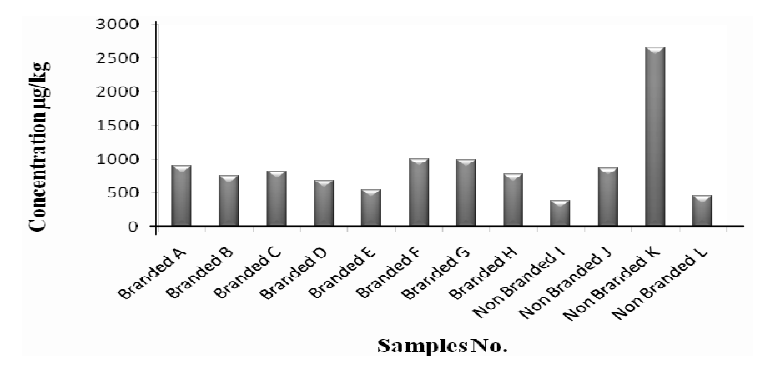

Figure 1. Concentartion of acrylamide in various chips samples

Acrylamide, a potent carcinogenic compound is produced in baked and fried food commodities due to Maillard reaction. In study conducted on French fries collected from Faisalabad and Lahore, it was found that acrylamide contents were higher (beyond permissible daily intake) in homemade and local vendor samples [26]. It is in contrast with present study in which; it is worth noted that acrylamide was in low concentration in sample obtained from local vendor while chips samples taken from mega store and branded samples have highest amounts of acrylamide.

The study conducted on different products showed that chocolate $(11.2 \%)$, bread $(23.5 \%)$ while French fries (29.9\%) are the major sources of dietetic acrylamide. Food commodities used among the three main meals of the day (so called snack type foods) added the most to the intake (42.2\%). So, the French fries may contain highest amounts of acrylamide which can harm human health [27].

The presence of acrylamide in potato chips can be linked with oil quality and processing time. Furthermore, different pre-treatments like freezing, frying and both can affect acrylamide formation and its reduction as well. Different ingredients may also enhance acrylamide concentrations. Such highest concentrations of acrylamide may impact health very badly as it found to be very prone to cancer.

\section{Conclusion}

The purpose of the present work was to search out the presence of acrylamide in potato chips of branded and non branded samples. It is concluded that acrylamide might be produced in the fried chips due to the chemical reaction started during high temperature cooking. Although differences are present in the amount of acrylamide among all samples but all have notable amount of acrylamide. Due to omnipresent nature of acrylamide it is necessary to take mitigation steps to avoid health hazardous issues due to acrylamide.

\section{References}

1. E. Tareke, P. Rydberg, P. Karlsson, S. Eriksson and M. Tornqvist, J. Agri. Food Chem., 50 (2002), 4998.

https://www.ncbi.nlm.nih.gov/pubmed/12166997

2. N. F. A. Swedish, Information about Acrylamide in Food, Swedish National Food Administration, 4 (2002) 24.

3. IARC. Acrylamide. IARC Monographs on the Evaluation of the Carcinogenic Risk of Chemicals to Humans, Lyon, France: International Agency for Research on Cancer, 60 (1994) 389.

4. C. J. Seal, A. De Mul, G. Eisenbrand, A. J. Haverkort, K. Franke, S. P. D. Lalljie, H. Mykkänen, E. Reimerdes, G. Scholz, V. Somoza and S. Tuijtelaars, Br. J. Nutr., 99 (2008) 1.

https://doi.org/10.1017/S0007114508965314

5. M. Biedermann and K. Grob, Mitteilungen aus Lebensmitteluntersuchung und Hygiene, 94 (2003) 406.

https://www.efsa.europa.eu/sites/default/files levent/documentset/141210-p05.pdf

6. M. Biedermann, A. Noti, B. Biedermann, V. Mozzetti and K. Grob, Mitteilungen aus Lebensmitteluntersuchung und Hygiene 93 (2002a) 668.

7. T. De Wilde, B. De Meulenaer, F. Mestdagh, Y. Govaert, W. Ooghe, S. Fraselle, K. Demeulemeester, C. Van Peteghem, A. Calus, J. M. Degroodt and R. Verhé, J. Agri. Food Chem., 54 (2006a) 2199. https://www.ncbi.nlm.nih.gov/pubmed/16536596

8. T. De Wilde, B. De Meulenaer, F. Mestdagh, Y. Govaert, S. Vandeburie, W. Ooghe, S. Fraselle, K. Demeulemeester, C. Van Peteghem, A. Calus and J. M. Degroodt, $J$. Agri. Food Chem., 53 (2005) 6550.

https://www.ncbi.nlm.nih.gov/pubmed/16076148 
9. T. De Wilde, B. De Meulenaer, F. Mestdagh, Y. Govaert, S. Vandeburie, W. Ooghe, S. Fraselle, K. Demeulemeester, C. Van Peteghem, A. Calus and J. M. Degroodt, J. Agri. Food Chem., 54 (2006) 404. https://www.ncbi.nlm.nih.gov/pubmed/16417297

10. N. Muttucumaru, J. S. Elmore, T. Curtis, D. S. Mottram, M. A. Parry and N. G. Halford, J. Agri. Food Chem., 56 (2008) 6167. https://www.ncbi.nlm.nih.gov/pubmed/1862 $\underline{4429}$

11. R. L. David, R. C. James and H. S. Richard, Annu. Rev. Food Sci. Tech., 3 (2012) 15. https://www.annualreviews.org/doi/abs/10.11 46/annurev-food-022811-101114

12. H. Terada and Y. Tamura, J. Food Hygc. Soc. Japan, 44 (2003) 303.

13. Y. Zhang, Y. Dong, Y. Ren and Y. Zhang, $J$. Chromatogr. A., 1116 (2006) 209. https://www.ncbi.nlm.nih.gov/pubmed/1658 $\underline{0677}$

14. M. R. Lee, L. Y. Chang and J. Dou, Anal. Chim. Acta, 582 (2007) 19.

https://www.ncbi.nlm.nih.gov/pubmed/1738 $\underline{6469}$

15. V. Gökmen and H. Z. Şenyuva, $J$. Chromatogr. A., 1120 (2006) 194. https://www.ncbi.nlm.nih.gov/pubmed/1646 $\underline{4456}$

16. P. Rydberg, S. Eriksson, E. Tareke, P. Karlsson, L. Ehrenberg and M. Tornqvist, $J$. Agri. Food Chem., 51 (2003) 7012. https://www.ncbi.nlm.nih.gov/pubmed/1461 $\underline{1163}$

17. N. Brunton, R. Gormley, B. Murray, F. Butler and E. Lummins, Status Report on Acrylamide in Potato Product, The National Food Centre-Teagasc (2005). https://www.researchgate.net/publication/277 $\underline{042342}$

18. E. C. SCF, Opinion of the scientific committee on food on new findings regarding the presence of acrylamide in food, European Commission Scientific Committee on Food (2002).
19. W. Claeys, B. De Meulenaer, A. Huyghebaert, M. L. Scippo, P. Hoet, and C. Matthys, Food Control, 59 (2016) 628. https://biblio.ugent.be/publication/8026662

20. F. Khoshnam, B. Zargar, N. Pourreza and H. Parham, J. Iranian Chem. Soc., 7 (2010) 853. https://link.springer.com/article/10.1007/BF0 3246079

21. Z. Geng, P. Wang and A. Liu, J. Chromatogr. Sci., 49 (2011) 818. https://www.ncbi.nlm.nih.gov/pubmed/2208 $\underline{0811}$

22. E. Hariri, M. I. Abboud, S. Demirdjian, S. Korfali, M. Mroueh and R. I. Taleb, J. Food Comp. Anal., 42 (2015) 91.

https://laur.lau.edu.lb:8443/xmlui/handle/107 25/4583

23. I. Pugajeva, L. Zumbure, A. Melngaile and V. Bartkevics, Determination of acrylamide levels in selected foods in Latvia and assessment of the population intake. In 9th Baltic Conference on Food Science and Technology "Food for Consumer WellBeing”, (2014) 111.

24. P. Singh, P. Singh, P. and R. B. Raja, African J. Biotech., 9 (2010) 8085. http://www.academicjournals.org/AJB

25. S. Razia, M. Bertrand, V. Klaus and G. L. Meinolf, Int. Food Res. J., 23 (2016) 21872192.

www.agris.upm.edu.my:8080/dspace/handle/ $\underline{0 / 13093}$

26. M. K. Iqbal Khan, A. Amjad, A. Maan, A. Nazir, M. Abrar, M. Abbas and A. M. Khan, Food Sci. Nutr. Tech. 2 (2017) 000124. https://medwinpublishers.com/FSNT/FSNT1 6000124.pdf

27. E. Dybing and T. Sanner, Toxicol. Sci., 75 (2003) 7-15. https://www.ncbi.nlm.nih.gov/pubmed/1280 $\underline{5639}$ 